Proc. of the X Int. Conf. - Ion Implantation and other Applications of Ions and Electrons, Kazimierz Dolny 2014

\title{
Effects of Irradiation with Low-Energy and High-Energy Krypton Ions on the Structure of TiCrN Coatings
}

\author{
S. Kislitsin ${ }^{a, *}$, I. GORLACHEV ${ }^{a}$ AND V. UGLOV ${ }^{b}$ \\ ${ }^{a}$ Institute of Nuclear Physics, Ibragimov Str., 1, 050032, Almaty, Kazakhstan \\ ${ }^{b}$ Belarusian State University, Nezaleznastia av., 4, 220030 Minsk, Belarus
}

\begin{abstract}
The results of surface structure investigations of $\mathrm{TiCrN}$ coating on carbon steel after irradiation by highand low energy krypton ions and successive two-hour vacuum annealing are reported in the present publication. Specimens with the TiCrN coatings of the $50 \div 100 \mathrm{~nm}$ thickness were formed by vacuum arc deposition techniques. The prepared specimens were irradiated by low energy $(280 \mathrm{keV})$ and high energy $(125 \mathrm{MeV})$ krypton ions. Study of surface structure was done by scanning electron microscopy and atomic force microscopy. X-ray diffraction and the Rutherford backscattering spectrometry were applied for determination of structure and coating thickness. After irradiation by high energy Kr ions there appear convexities of spherical shape with dimensions $10 \div 30 \mathrm{~nm}$ on the surface of the coating. Subsequent two-hour vacuum annealing led to decrease of convexities dimensions. Irradiation by low-energy $\mathrm{Kr}$ ions does not lead to significant changes in the structure of the coating surface. Only traces of surface sputtering are found. Explanation of the observed surface damage is proposed. Convexities are the traces of ions passing through coating and appear due to structural reconstruction at energy release along a trajectory of ions braking. As the projective range of high energy Kr ions exceeds coating thickness, then damage of structures is generated in the substrate and convexities are the traces of undersurface damages.
\end{abstract}

DOI: 10.12693/APhysPolA.128.818

PACS: $61.80 . \mathrm{Lj}$

\section{Introduction}

Development of nuclear power shows increased requirements for structural materials, technologies of their manufacture and the control of serviceability. Creation of new structural materials is a current problem of creating new generation reactors. Development of advanced structural materials proceeds in several directions, such as development of oxide dispersed strengthened (ODS) ferrite martensite steels, high nickel content alloys of nimonic PE-16 type, austenite steels with special dopants.

Alongside these directions, development of materials with protective coatings possessing high physicalmechanical properties, used for protection of the basic material from radiation, thermal and aggressive environment impact is considered as a perspective. Ceramic coatings are now being used to increase the resistibility of structural steels for high-temperature reactors to radiation embrittlement and swelling $[1,2]$. Among them, the special attention is paid to nitrides of transition metals. They represent the greatest interest for the use as protective radiation-resistant materials in the nuclear-power installations of generation III + and IV $[3,4]$. Interest in nitrides of transition metals is due to their special physical and mechanical properties, combining both properties of ceramics and metals. Coatings based on nitrides of the transition metals possess the enhanced hardness, wearand corrosion resistance, thermal stability [5-7] that allow considering them as perspective protection for struc-

*corresponding author; e-mail: skislitsin@mail.ru tural materials. Nitride coatings have already been examined as a perspective for covering of surface cladding of gas-cooled fast reactors (GFR) [8] and it makes current studies of their radiation resistance. As follows from our investigations, the best results were found for the multicomponent composite coatings based on the solid solutions of nitrides of several transition metals $(\mathrm{Ti}-\mathrm{Cr}-\mathrm{N}$, Ti-Zr-N, Ti-Mo-N and others) [9, 10]. However, stability of the physical-mechanical properties of such coatings under irradiation is insufficiently studied that impedes their possible use as radiation-resistant protective coatings. The objectives of this work are to study changes in the surface structure of TiCrN coatings caused by krypton irradiation simulating fission fragments of nuclear fuel.

\section{Experimental procedure and specimens preparation}

Titanium-chromium-nitrogen coatings were deposited on the surface of carbon steel $(<0.2 \mathrm{wt} \% \mathrm{C})$ substrates by vacuum arc deposition with ion bombardment (VAD). The VAD regimes were as follows: $\mathrm{Ti}$ and $\mathrm{Cr}$ cathodes, residual nitrogen pressure $p_{N}=10^{-1} \mathrm{~Pa}$, bias voltage of $60 \mathrm{~V}$, cathode current of $100 \mathrm{~A}$, deposition time of $1, \ldots, 2$ min. The series of TiCrN coatings with an approximately equal content of titanium and chromium on carbon steel, with a thickness of 50-100 nm, were formed. The procedure of coating formation is presented in detail in papers $[5,7]$. The specimens were disks with a diameter of $15 \mathrm{~mm}$ and thickness of $\approx 1 \mathrm{~mm}$.

Structure, thickness and surface morphology of the coatings were studied by X-ray diffractometry (XRD), Rutherford backscattering spectrometry with protons 
(RBS), scanning electron microscopy (SEM) and atomic force microscopy (AFM).

Analysis of coating element content, by using the energy dispersive X-ray microanalysis (EDXA) shows that the coating composition is a compound of titanium, chromium and nitrogen with the titanium content $52.51 \pm 0.07$ at. $\%$ and with the chromium content $47.49 \pm 0.07$ at. $\%$, see Table I.

TABLE I

Element content obtained by the processing of EDXA spectra.

\begin{tabular}{c|c|c}
\hline \hline \multirow{2}{*}{ Element } & \multicolumn{2}{|c}{ Content [at. \%] } \\
\cline { 2 - 3 } & Coating & Substrate \\
\hline $\mathrm{Fe}$ & - & $99.05 \pm 0.22$ \\
$\mathrm{Si}$ & - & $0.37 \pm 0.19$ \\
$\mathrm{Ti}$ & $52 \pm 0.1$ & - \\
$\mathrm{Cr}$ & $48 \pm 0.1$ & - \\
$\mathrm{Mn}$ & - & $0.58 \pm 0.02$
\end{tabular}

Irradiation of specimens with the $\mathrm{TiCrN}$ coating by krypton ions was performed using the heavy ion cyclotron DC-60 of Astana branch of INP. Irradiation of specimens by krypton ions $\left({ }^{84} \mathrm{Kr}^{14+}\right)$ with energy of $1.5 \mathrm{MeV} /$ nucleon was performed on a high energy channel of the cyclotron DC-60. The total ion energy was equal to $\approx 125 \mathrm{MeV}$, the fluence $F=5 \times 10^{14} \mathrm{ion} / \mathrm{cm}^{2}$, the irradiation temperature did not exceed $150{ }^{\circ} \mathrm{C}$. In the case of low energy ${ }^{84} \mathrm{Kr}^{14+}$ (ECR source) the ion energy was $20 \mathrm{keV} /$ charge, i.e. full ion energy was $280 \mathrm{keV}$, fluence $F=5 \times 10^{16}$ ions $/ \mathrm{cm}^{2}$, irradiation temperature did not exceed $150^{\circ} \mathrm{C}$.

Coatings thickness was measured by the RBS method. The example of backscattered protons spectrum and its approximation for carbon steel with the TiCrN coating is shown in Fig. 1.

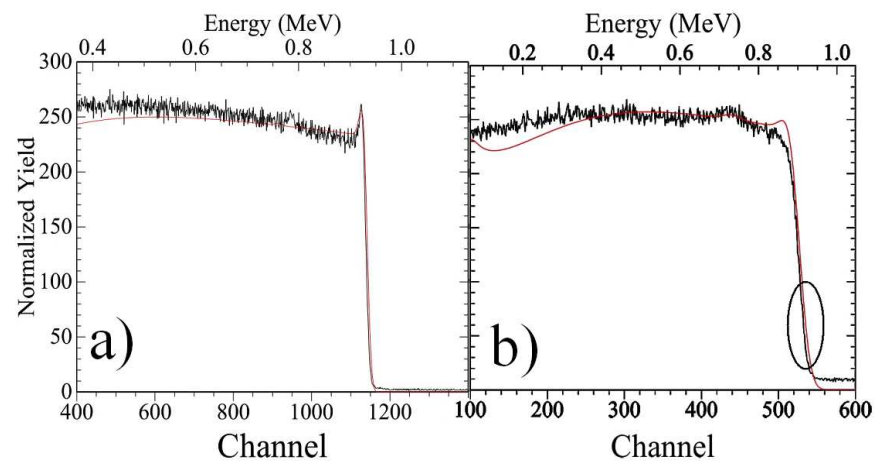

Fig. 1. RBS spectra of specimens with TiCrN coating on carbon steel: (a) unirradiated, (b) irradiated by $280 \mathrm{keV}$ krypton ions.

The results of treatment of spectrum are given in Fig. 1 and Table II. According to data from Table II coating contains $\mathrm{Ti}$ and $\mathrm{Cr}$ in approximately equal amounts and thickness of $\mathrm{TiCrN}$ coating constitutes $50 \mathrm{~nm}$.

\section{TABLE II}

Estimated values of element contents along the distance from the surface for unirradiated specimen of carbon steel with the TiCrN coating.

\begin{tabular}{c|c|c|c|c}
\hline \hline \multirow{2}{*}{ Distance from surface, $[\mathrm{nm}]$} & \multicolumn{4}{|c}{ Content [at.\%] } \\
\cline { 2 - 5 } & $\mathrm{Cr}$ & $\mathrm{Ti}$ & $\mathrm{N}$ & $\mathrm{Fe}$ \\
\hline$<50$ & 40 & 40 & 20 & 0 \\
$>50$ & 0 & 0 & 0 & 100
\end{tabular}

\section{Experimental results and discussion}

\subsection{Effect of high-energy krypton ions irradiation on the structure of $\mathrm{TiCrN}$ coating}

Crystalline structural and phase stability. Chromium and titanium atoms belong to transition metals. Titanium with chromium is unlimitedly soluble in each other in liquid state. As the temperature decreases, the $\mathrm{Ti}-$ Cr alloys crystallize to form a continuous series of solid solutions (Fig. 2). The main transformations occur in the solid state [11]. Therefore, close to composition of $\mathrm{TiCr}_{2}$, intermediate phases with the structure of the Laves phases are formed [11].

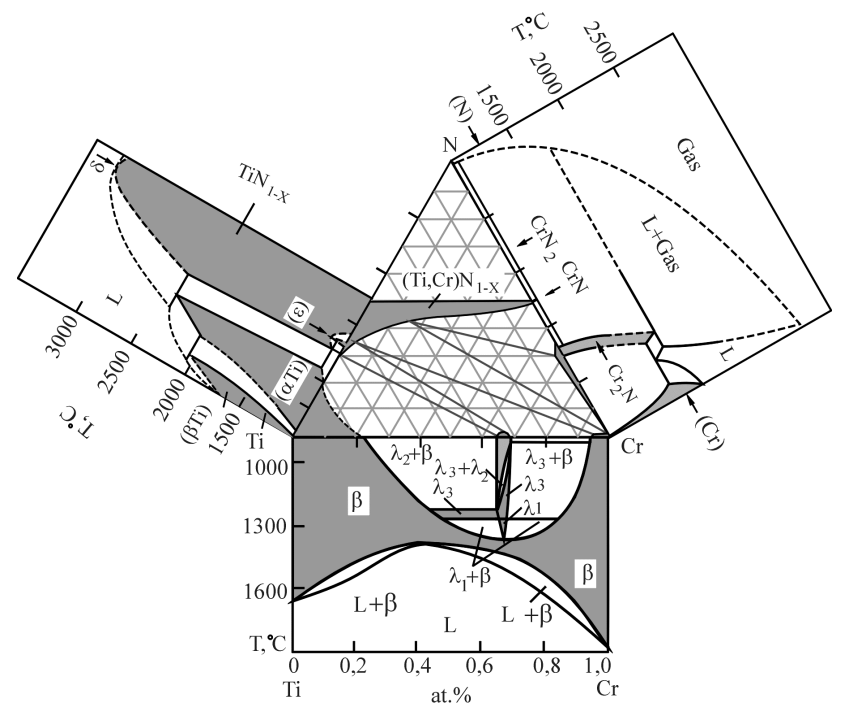

Fig. 2. Binary phase diagram of $\mathrm{Cr}-\mathrm{Ti}, \mathrm{Cr}-\mathrm{N}, \mathrm{Ti}-$ $\mathrm{N}$ [11] systems and isothermal cross-section of a ternary system $\mathrm{Cr}-\mathrm{Ti}-\mathrm{N}$ at $1000^{\circ} \mathrm{C}$ [12]. Single-phase regions are marked by the gray color on the diagrams.

In binary system of nitrogen with transition metals: $\mathrm{Ti}$ and $\mathrm{Cr}$ of the equiatomic composition, the compounds with the structure $\mathrm{B} 1$ (prototype of $\mathrm{NaCl}$ crystalline structure) are formed, see Fig. 2. Compounds $\mathrm{TiN}_{1-x}$ and $\mathrm{CrN}_{1-x}$ belong to a class of disordered nonstoichiometric nitrides with a wide range of homogeneity (Fig. 2) [13]. In these compounds the metal atoms form fcc sublattice, while octahedral sites can be occupied by interstitial nitrogen atoms or vacancies. The type of crystal structure of disordered nonstoichiometric compounds 
does not change with concentration of structural vacancies and this causes the wide interval of homogeneity.

The third element of the $\mathrm{Cr}-\mathrm{Ti}-\mathrm{N}$ system, the nitrogen is significantly different in chemical properties than the metals forming the compound. Compound of nitrogen with transition metals $\mathrm{Ti}$ and $\mathrm{Cr}$ may form an ordered structure. Compounds $\mathrm{Cr}-\mathrm{Ti}-\mathrm{N}$ are formed from the solid solution and can generate phases of variable composition. Nitrides $\mathrm{TiN}_{1-x}$ and $\mathrm{CrN}_{1-x}$ are completely mutually soluble in the ternary $\mathrm{Ti}-\mathrm{Cr}-\mathrm{N}$ compound and form continuous solid solutions (Fig. 2). Nitride (Ti, $\mathrm{Cr}$ ) $\mathrm{N}_{1-x}$ has a cubic structure $B 1$ (prototype of $\mathrm{NaCl}$ structure) with a wide range of homogeneity [13].

As shown in [5], the chromium-titanium-nitrogen coatings deposited on the metallic substrate by the VAD method at $450-500^{\circ} \mathrm{C}$, constitute solid solution ( $\mathrm{Ti}$, $\mathrm{Cr}) \mathrm{N}_{1-x}$ with fcc lattice. Formed by condensing of combined plasma streams of titanium and chromium in nitrogen atmosphere, the phase composition of the TiCrN coatings represents the mixture of phases, content of which varies from $(\mathrm{Ti}, \mathrm{Cr}) \mathrm{N}+\mathrm{Cr}$ to $\mathrm{TiN}+(\mathrm{Ti}, \mathrm{Cr}) \mathrm{N}$ with increase of the relative atomic concentrations of titanium to chromium. Thus increasing the chromium content leads to formation of a mixture of phases of solid solution $(\mathrm{Ti}, \mathrm{Cr}) \mathrm{N}$ and $\mathrm{Cr}$, the increase of titanium content leads to formation of a mixture of phases solid solution (Ti, Cr)N and TiN.

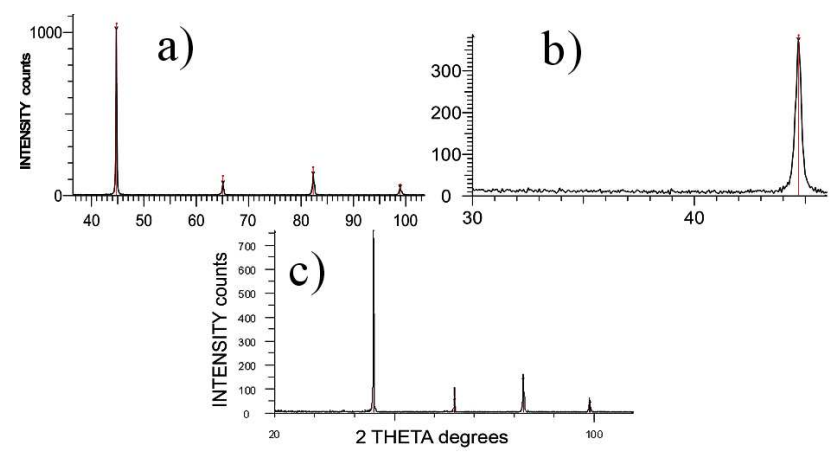

Fig. 3. Diffractograms of TiCrN coating on steel: before irradiation (a) in the Bragg-Brentano geometry, (b) grazing beam, (c) in the Bragg-Brentano geometry after irradiation by ${ }^{84} \mathrm{Kr}^{14+}$ with energy $125 \mathrm{MeV}$ to a fluence of $5 \times 10^{14}$ ion $/ \mathrm{cm}^{2}$.

Note that in [5] the procedure of synthesis of $\mathrm{TiCrN}$ coatings is discussed and the results are presented of a crystalline structure study for coatings of a $1 \mu \mathrm{m}$ thickness and more. In this work we conducted research of samples with the TiCrN coatings deposited by the same procedure as in [5] but with thickness of $\approx 50 \mathrm{~nm}$. Studies of the structure of the synthesized TiCrN coatings with thickness $\approx 50 \mathrm{~nm}$ by XRD before irradiation showed that only reflexes from carbon steel are observed on the diffractogram, both in the Bragg-Brentano geometry and grazing geometry, see Fig. 3a,b. At the same time RBS method shows thickness of $\mathrm{TiCrN}$ coating equal to $50 \mathrm{~nm}$, see Table II. Possible explanation of such discrepancies is following - small thickness of coating does not allow revealing its crystal structure.

The studies of the coating structures after irradiation by ${ }^{84} \mathrm{Kr}^{14+}$ with the energy $1.5 \mathrm{MeV} /$ nucleon to a fluence of $5 \times 10^{14} \mathrm{ion} / \mathrm{cm}^{2}$ by XRD showed no significant changes in the structure of the coating and the substrate. Only the reflections of bcc lattice of steel with small broadening of the diffraction peaks are in the diffractograms. The RBS study of element distribution along the distance from the coating surface revealed no significant changes of coating thickness; the spectrum of irradiated specimen is similar to that of unirradiated one. Moreover on the spectrum of backscattered protons there is no peak from implanted krypton. This is due to the fact that the projective range of krypton ions with the energies of $\approx 125 \mathrm{MeV}$ exceeds almost twice the $1 \mathrm{MeV}$ range of protons at the analysis of the structure by the RBS method.

Effect of irradiation with high-energy krypton ions and subsequent annealing on the surface morphology of the $\mathrm{TiCrN}$ coating. The most evident influence of irradiation with high-energy ions of krypton is revealed in changes of the surface morphology of TiCrN coating. The surface structure before irradiation and after irradiation was investigated by AFM and SEM.

The AFM images of the surface structure of both unirradiated and irradiated samples are shown in Fig. 4. As can be seen in Fig. 4a,b before irradiation the average surface roughness does not exceed $35 \mathrm{~nm}$. But on a background of rather smooth surface can be observed higher protrusions of technological origin. As follows from comparison of Fig. 4a and b, the surface structure of the coating before and after irradiation by krypton ions is considerably different. After irradiation, on the background of relatively smooth coating surface there are observed the hillocks of spherical shape, height of which is $\approx 30 \mathrm{~nm}$ and the diameter of the order of tens of nanometers. Height of technological protrusions is significantly larger.
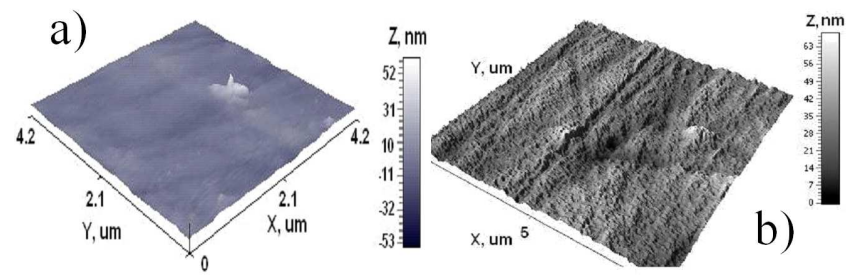

Fig. 4. Surface structure of TiCrN: (a) before irradiation by krypton ions, (b) after irradiation by high energy krypton ions.

Figure 5 presents the results of SEM study of coatings surface, which shows the structure before irradiation (Fig. 5a) and after irradiation (Fig. 5b and c).

Comparison of the surface structure in Fig. 5a and Fig. 5b,c shows appearance of the convexities on the irradiated surface of coating, which can be interpreted as traces of incident krypton ions passing through the coating. This confirms those obtained by the AFM 


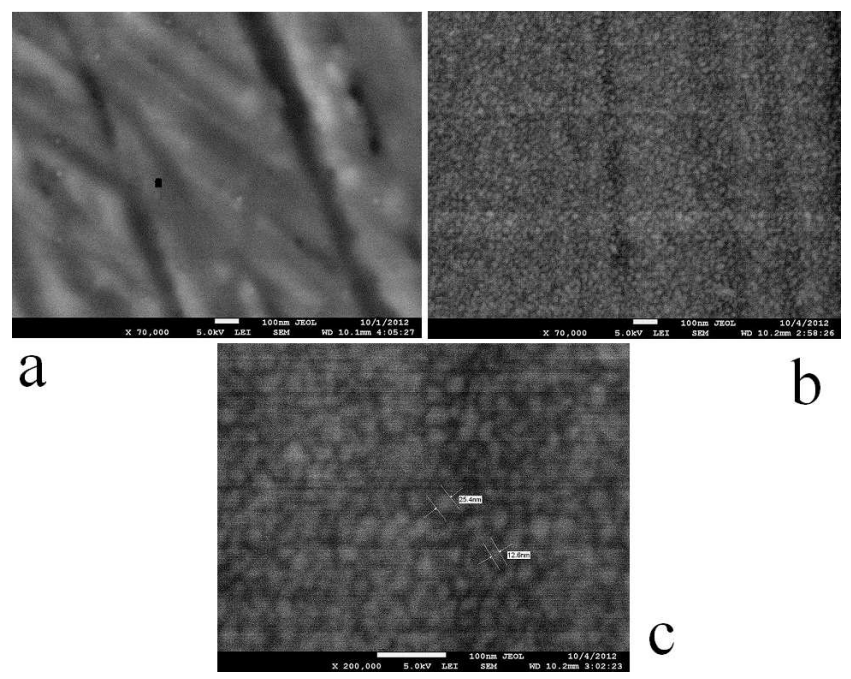

Fig. 5. SEM photographs of the surface of TiCrN coating: (a) before irradiation, magnification $70,000 \times$, (b, c) after krypton irradiation, magnification $70,000 \times$ and $200,000 \times$, respectively.

studies. The diameter of convexities observed on the surface reaches from $13 \mathrm{~nm}$ up to $26 \mathrm{~nm}$. Overlapping of some convexities is visible from the image in Fig. 5c, apparently it is the result of close passing ions. The calculated surface density of convexities is about two orders smaller than ion fluence, however we believe that the surface density of convexities correlates with the fluence of bombarding ions. Correlation is understood here in the sense that, as our experiments show, with decrease of ion fluence, the density of convexities on the surface decreases.

The coated samples irradiated by krypton ions were subjected to a two-hour serial vacuum annealing at a temperature of $400 \pm 5^{\circ} \mathrm{C}, 500 \pm 5^{\circ} \mathrm{C}$ and $600 \pm 5^{\circ} \mathrm{C}$. The SEM images of irradiated coating surface after annealing are presented in Fig. 6.

Figure 6 shows evolution of surface structure, namely, reduction of the size of convexities formed under irradiation. As seen from Fig. $6 \mathrm{~b}$ and c, annealing at $400^{\circ} \mathrm{C}$ leads to reduction of the convexities size and next annealing at $500{ }^{\circ} \mathrm{C}$ leads to an almost complete their disappearance. Note also that the coating delaminating or opening the convexities on the surface was not observed after irradiation or after subsequent annealing in the temperature range $400 \div 600{ }^{\circ} \mathrm{C}$.

\subsection{Effect of low-energy krypton ions irradiation on the structure of $\operatorname{TiCrN}$ coating}

Investigations of structure and surface morphology after low energy krypton ion irradiation were carried out in the same way as after high energy krypton ion irradiation.

Studies of the coating structures after irradiation by ${ }^{84} \mathrm{Kr}^{14+}$ with the energy $20 \mathrm{keV} /$ charge to a fluence of $5 \times 10^{16}$ ions $/ \mathrm{cm}^{2}$ by X-ray diffractometry showed no significant changes in the structure of the coating and

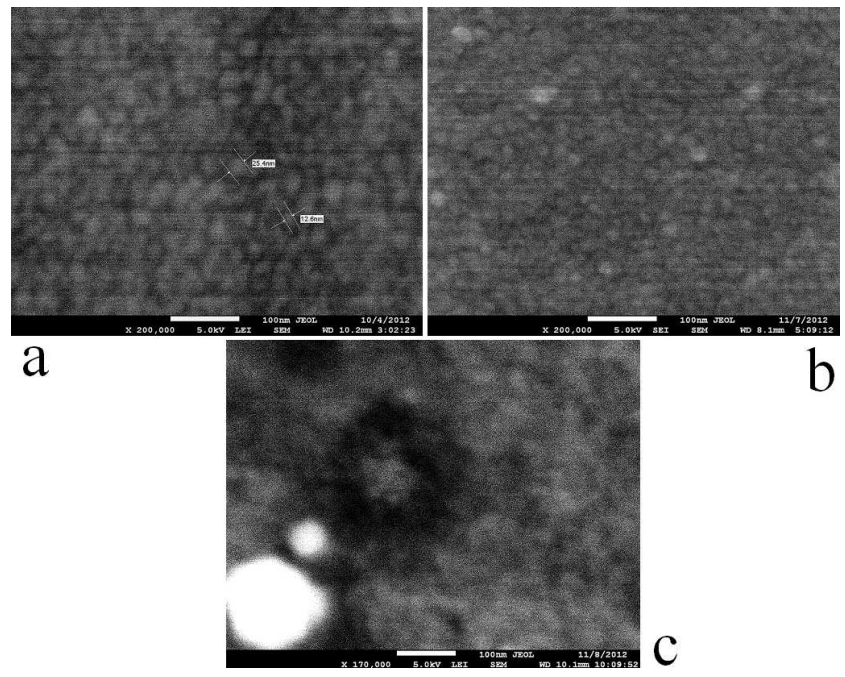

Fig. 6. SEM photographs of the surface of TiCrN coating after post irradiating successive $2 \mathrm{~h}$ isochronal annealing: (a) after krypton irradiation, before annealing, magnification $200,000 \times$, (b) after $2 \mathrm{~h}$ annealing at $400 \pm 5{ }^{\circ} \mathrm{C}$, magnification $200,000 \times$, (c) after next $2 \mathrm{~h}$ annealing at $500 \pm 5^{\circ} \mathrm{C}$, magnification $170,000 \times$.

the substrate. As in the case of high energy krypton ions irradiation, only the reflections of bcc lattice of carbon steel with small broadening of the diffraction peaks are in diffractograms. The diffractogram of the coating irradiated by low energy $\mathrm{Kr}$ ions is similar to that in Fig. 3c.

The RBS study showed significant reduction of coating thickness. From Fig. 1b, which represents the spectrum of backscattered protons, one can conclude that it is impossible to separate the coating from substrate because of small thickness of coating. It means reducing of coating thickness due to surface sputtering. In the spectrum of backscattered protons a signal from the implanted krypton is not observed. It can be explained, firstly, by the surface sputtering, when implanted krypton atoms are sputtered together with the atoms of coating. Secondly, the signal of backscattered protons from the krypton atoms overlaps the signal from protons backscattered on iron atoms of the substrate. Location of signal from the protons backscattered on krypton atoms should be in the region marked by the circle in Fig. $1 b$.

The investigations of the surface morphology by means of AFM and SEM confirm the results of XRD and RBS studies. The structure of surface irradiated by low energy krypton ions has no features characteristic of surface irradiated by high energy krypton ions. No convexities were found on the irradiated surface; only traces of surface sputtering were observed, see Fig. 7.

Traces of sputtering manifested in a smoother surface after low energy krypton ions irradiation. Subsequent two hour isochronous annealing of irradiated samples does not lead to noticeable change of surface structure, see Fig. 7c. 


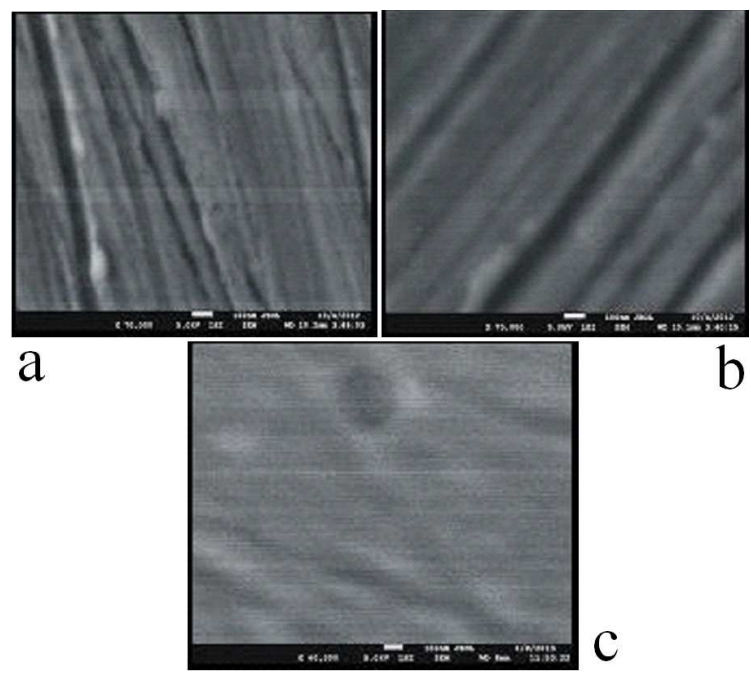

Fig. 7. SEM photographs of the TiCrN surface: (a) unirradiated, magnification $70,000 \times$; (b) after low energy krypton ion irradiation, magnification $70,000 \times$; (c) after two-hour annealing at $400 \pm 5^{\circ} \mathrm{C}$, magnification $60,000 \times$.

\subsection{Discussion}

In our opinion, the mechanisms of radiation damage of samples with the TiCrN coating at low- and high energy irradiation is considerably different. At high energy krypton irradiation on the coating surface there appear convexities of spherical shape, the height of which is 10 $30 \mathrm{~nm}$ and the diameter is of the order of tens of $\mathrm{nm}$. Apparently, these convexities are the traces on the surface from bombarding particles. Energy release along the trajectory of moving ion led to formation of structural changes, i.e. formation of latent track, the trace of which can be found on the surface - convexity. As the projective range of ${ }^{84} \mathrm{Kr}$ ions with the energy $125 \mathrm{MeV}$ is $8 \mu \mathrm{m}$, main damages occur in the substrate, i.e. in carbon steel. Energy loss leads to local heating of steel and distortion of material along the ion trajectory and it is manifested in the appearance of convexities on the surface. Krypton ions occupy the vacant lattice sites, generated at implantation. Due to a sufficiently high migration energy (higher than the energy of self-diffusion of the iron atoms) and relatively low temperature under irradiation $\left(\leq 150^{\circ} \mathrm{C}\right)$ krypton atoms are almost immobile and do not form gas bubbles. Subsequent annealing led to recovery of structural changes and to decrease of convexities dimensions on the surface. This is unlike to the behaviour of highly mobile helium atoms that form helium bubbles which move to the surface of the material at elevated temperatures and cause blistering and surface flaking [14].

A quite different mechanism of radiation damage takes place at irradiation by low energy krypton ions. In this case a main mechanism is surface sputtering. According to the SRIM calculations, a projective range of ${ }^{84} \mathrm{Kr}^{14+}$ with the energy $280 \mathrm{keV}$ is $80 \mathrm{~nm}$ and comparable with coating thickness. The TiCrN sputtering yield of $280 \mathrm{keV}$ $\mathrm{Kr}$ ions is $4.1 \mathrm{at} / \mathrm{ion}$. The calculated decrease of coating thickness at the ion fluence $5 \times 10^{16} \mathrm{~cm}^{-2}$ is $\Delta h \approx 35 \mathrm{~nm}$. Small energy loss of krypton ions and the surface sputtering prevent appearance of convexities on the surface and $\mathrm{Kr}$ accumulation. This is also in contrast with the low energy alpha-particles irradiation when surface sputtering is small and helium accumulates in the subsurface layers causing formation of gas bubbles and blisters [14].

\section{Conclusion}

The results of experimental studies of irradiation by low and high energy krypton ions on the structure of thin TiCrN coatings can be formulated as follows:

1. After irradiation by high energy Kr ions on the surface of thin $\mathrm{TiCrN}$ coating there appear spherical convexities, dimensions of which are $10 \div 30 \mathrm{~nm}$ and the surface density depends on the ion fluence. Series of consistent isochronal annealing in the temperature interval $400-600^{\circ} \mathrm{C}$ leads to decreasing sizes of convexities on the surface.

2. Explanation of the observed surface damage is following: convexities on the surface are generated at ion bombardment and are traces of ions passing through coating and steel substrate. Convexities appear due to structural reconstruction at energy release along a trajectory of ion stopping. Recovery of the structural damages during vacuum annealing resulted in decrease of convexities dimension on the surface.

3. Irradiations by low-energy Kr ions do not lead to significant changes in the structure of the coating surface, only sputtering of the surface takes place. Because of rather high sputtering yield of $280 \mathrm{keV}$ Kr ions, krypton does not accumulate in material and sputter together with coating.

\section{Acknowledgments}

The work was performed in the framework of the grant 2789/GF3 of the Ministry of Education and Science RK.

\section{References}

[1] K.L. Murty, I. Charit, J. Nucl. Mater. 383, 189 (2008).

[2] Y. Kurata, H. Sato, H. Yokota, T. Suzuki, in: Structural Materials for Innovative Nuclear Systems. Workshop Proc. Daejon 2010, OECD, NEA, Vol. 6896, 2012, p. 177.

[3] A. Ciriello, V.V. Rondinella, D. Staicu, J. Somers, J. Nucl. Mater. 371, 129 (2007).

[4] A.A. Andreev, V.N. Voevodin, O.V. Sobol, V.F. Gorban, G.N. Kartmasov, V.A. Stolbovoi, D.V. Lysan, Problems Radiat. Sci. Technol. Phys. Radiat. Eff. Radiat. Mater. Sci. N5(87), 142 (2013) (in Russian). 
[5] V.V. Uglov, V.M. Anischik, S.V. Zlotski, G. Abadias, S.N. Dub, Surf. Coat. Technol. 200, 178 (2005).

[6] A.L. Ivanovskii, Chem. Progr. 65, 499 (1996) (in Russian).

[7] V.V. Uglov, V.M. Anischik, V.V. Khodasevich, M.M. Danilionak, D.P. Rusalsky, V.A. Ukhov, Vacuum 81, 1345 (2007).

[8] S. Gavarini, N. Toulhoat, C. Peaucelle, P. Martin, J. Mende, Y. Pipon, H. Jaffrezic, J. Nucl. Mater. 362, 364 (2007).

[9] V.V. Uglov, D.P. Rusalski, S.V. Zlotski, A.V. Sevriuk, G. Abadias, S.B. Kislitsin, K.K. Kadyrzhanov, I.D. Gorlachev, S.N. Dub, Surf. Coat. Technol. 204, 2095 (2010)

[10] S. Kislitsin, K. Kadyrzhanov, V. Uglov, D. Rusalski, G. Abadias, S. Dub, in: Structural Materials for Innovative Nuclear Systems, Workshop Proc., Daejon 2010, OECD, NEA, Vol. 6896, 2012, p. 87.
[11] Handbook on Binary State Diagrams of Metallic Systems, Ed. N.P. Lyakishev, Mashinostroenie, Moscow 1997, Vol. 2, p. 1024 (in Russian).

[12] H. Holleck, Binäre und ternäre Binary and Ternary Carbide and Nitride Systems of Transition Metals, Borntraeger Brothers, Berlin 1984, p. 295 (in German).

[13] A.I. Gusev, A.A. Rempel, Non-Stoichoimetry, Disorder and Order in Solids, UB RAS, Ekaterinburg 2001 (in Russian).

[14] S.B. Kislitsin, I.D. Gorlachev, V.V. Uglov, in: $A b-$ stracts IX Int. Conf. Nuclear and Radiation Physics, Almaty 2013, Eds. E.G. Batyrbekov, P.V. Chakrov, INP, Almaty 2013, p. 81 (in Russian). 